\title{
DYNAMIC PROPERTIES AND WEAR ANALYSIS OF A RAIL VEHICLE WITH WHEELS' SELF-LUBRICATING COATINGS
}

\author{
Rafał Melnik ${ }^{1 * *}$, Andrzej Chudzikiewicz², Seweryn Koziak ${ }^{3}$, Michał Opala ${ }^{3}$, Ján Dižo ${ }^{4}$ \\ ${ }^{1}$ Faculty of Computer Science and Food Science, Lomza State University of Applied Sciences, Lomza, Poland \\ ${ }^{2}$ Faculty of Transport, Electrical Engineering and Computer Science, Kazimierz Pulaski University of Technology \\ and Humanities in Radom, Radom, Poland \\ ${ }^{3}$ Faculty of Transport, Warsaw University of Technology, Warsaw, Poland \\ ${ }^{4}$ Department of Transport and Handling Machines, Faculty of Mechanical Engineering, University of Zilina, Zilina, \\ Slovakia
}

*E-mail of corresponding author: rmelnik@pwsip.edu.pl

\section{Resume}

The problem of wheel and rail wear in railway transport generates costs of reprofiling and availability of vehicles and infrastructure. One of the possibilities of wear minimizing is decreasing of the friction coefficient in wheel-rail contact by means of lubricants. Such a solution has drawbacks from which the most crucial are: decrease of tractive/braking forces and difficulties with the precise spreading of the lubricant. These disadvantages may be avoided by modern, innovative self-lubricating coatings, applied at the production stage on the wheel flanges. The aim of the study is to investigate the effect of self-lubricating coatings on a rail vehicle's dynamic behaviour, safety against derailment and predicted wheel wear. The numerical study was performed using the wagon multibody model with simulated self-lubricating coating on wheel flanges.

Available online: https://doi.org/10.26552/com.C.2021.1.B22-B32

\section{Article info}

Received 31 March 2020

Accepted 19 June 2020

Online 30 October 2020

\section{Keywords:}

rail vehicle, goods wagon, self-lubricating coating, dynamics, multi-body system, safety against derailment, wear

ISSN 1335-4205 (print version) ISSN 2585-7878 (online version)

\section{Introduction}

Since the beginning of the rail transport expansion, wheel and rail wear has been one of the most significant technical problems in this mode of transport. Wear is not only a great economic burden for vehicles and tracks operators, yet it gives rise to the additional actions for wheels reprofiling and rails grinding, hence it may limit the availability of infrastructure and the rolling stock. Another adverse feature, related to the worn wheels' profiles, is affecting the vehicle dynamic behaviour, which may lead to reduction of safety against derailment [1]. Minimizing the phenomenon of wear has become a common goal of vehicle and rail infrastructure operators. Unfortunately, with the global tendency to increase the axle loads in railway goods transport, accelerated degradation of tracks and vehicle wheels should be expected, especially on routes with numerous small-radii curves. In such conditions (smallradii curves), the wheel slip values are high and additional frictional forces arise due to the wheel flange-rail head contact, what in turn increases the total resistive force and wear of the contacting surfaces.

The most common solution to the problem of the wheel/rail wear, used worldwide, is lubrication. In the case of goods, rail transport is nowadays the only economically acceptable means for the wheel-rail wear reduction, without running gear modification. Passenger rolling stock, especially trams, metro and multiple units are subject of studies aiming to develop the new running gear solutions facilitating curves negotiation [2-4]. To eliminate the problems of external lubricants and exploit advantages of decreased friction coefficient, it was decided to focus on the possibility of applying an innovative thin layer of self-lubricating coating on the wheel flange. The wheelsets with self-lubricating coatings are a new, innovative solution and thus neither has been adopted in the railway transport nor tested in real conditions. However, with decrease of the friction coefficient, depending on the wheels' lateral position relative to rails, vehicle's dynamic behaviour may be affected, since friction is a crucial factor in the process of contact forces generating. The aim of the presented study was to investigate dynamic responses and predict the wear rate of a two-axle goods wagon multibody model with simulated self-lubricating layers applied on wheels' flanges. This novel application of coating reducing friction required to include its mathematical description in the wheel-rail contact modelling. 


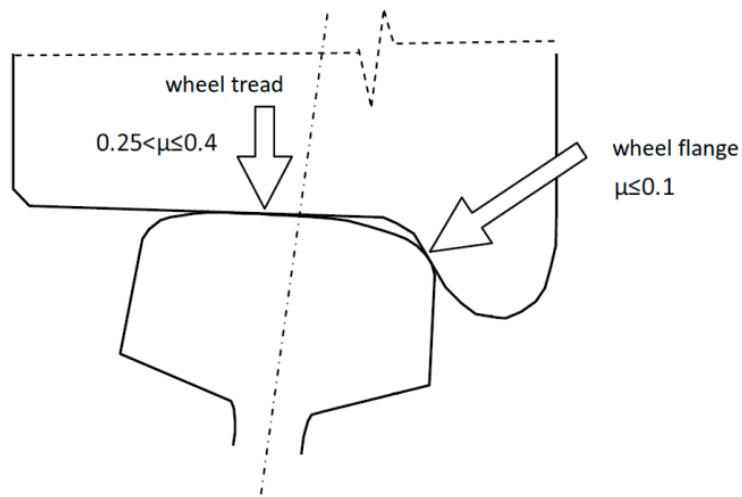

Figure 1 Required friction coefficient values in the wheel-rail contact

\section{Wheel-rail friction modification}

The necessity of friction coefficient modification of the wheel-rail contact is related to wear phenomenon. The rate of wear is strongly influenced by the values of the contact stresses, size of the contact being in slip and use of lubricants applied intentionally or occurring naturally (water, snow, etc.). Wear, as a result, leads to the changes of wheel and rail profiles. If the tangential force, generated in the contact patch, were greater than adhesion, determined by the friction coefficient, there will be a slip resulting in a significant increase of wear of the elements. Wear minimisation through friction modifiers is effective, nevertheless, it should be kept in mind that improper application may lead to the intensification of the wear process in a contact zone [5]. The required friction coefficient values, being a trade-off between low wear and ability to exert the high tractive/braking forces in the wheelrail contact, are depicted in Figure 1.

In order to apply lubricant to area of the slipping contacting surfaces, three types of systems are usually used [6]:

- mobile systems - commonly in the form of specially adapted railway vehicles that lubricate rails,

- trackside devices - mounted in the vicinity of track in which the release of the lubricant is triggered by the passing vehicle and

- on-board devices - eject lubricant directly to the wheel flange, from where it flows into the area of contact between the wheel and the rail.

Effectiveness of some solutions of applying a lubricant is limited, as evidenced by Nilsson [7], to a distance of about $200 \mathrm{~m}$ from the last application. The way to eliminate disadvantages of using current methods of reducing the friction coefficient, which are:

- limited range of impact;

- the need for calibration;

- requirement for precise dosing;

- danger of failure of the lubricant distributing to the entire rolling surface, resulting in a critical decrease of tractive/braking forces;

the need to refill the lubricant, etc.

could be use of the self-lubricating coatings applied to the wheel flange. The self-lubricating coatings have been successfully utilized in many cases in which the friction coefficient modification is required, without interfering the materials of contacting surfaces. Preliminary laboratory test stand studies on a full-scale wheelset carried out by the Plasma Systems have shown significantly lower flange wear by using thin brass layer - from $0.89 \mathrm{~mm}$ to $0.09 \mathrm{~mm}$ [8]. Similar effects are observed in the case of the rail.

\section{$3 \quad$ Rail vehicle dynamics modelling}

\subsection{General approach}

In the case of a simulation analysis of the rail vehicle dynamics and wheel profile wear, it is necessary to create mathematical models of a vehicle, rolling contact and the track. Literature on modelling the rail-track vehicle system is abundant and diverse. One can distinguish three basic subsystems of the aforementioned system, such as track, contact zone with rail and rail vehicle. The problem of the track modelling can be found in such works as [9-11]. The issues of rail vehicle dynamics and wheel-rail contact modelling are discussed in the works, e.g. [12-18]. Damages of vehicles' running gear elements and their effect on dynamic behaviour are analysed by [19-22]. The mechanism of phenomena, occurring in the contact zone, is an interest of tribologists and researchers dealing with wearing of materials in the contact area [23-26]. It should be noted that there is no global theory explaining the mechanism of wear in general, also including the wheel-rail contact.

Investigation of dynamic properties of a rail vehicle as a mechanical system should begin with presentation of its physical model (Figure 2), whose dynamic properties are described by equations of motion.

This general model belongs to the group of the "lowfrequency" models. It is assumed that the upper limit of the low-frequency vibration range is about $25 \mathrm{~Hz}$ [13]. Inertial objects of the vehicle - wheelsets and body - performing low-frequency vibrations behave like rigid bodies. These solids are connected by means of massless suspension elements: springs and dampers, whose characteristics can be linear or nonlinear. Sources of vibrations in the rail vehicle-track system are, in the considered issue, geometric irregularities of the track and inertial forces. 


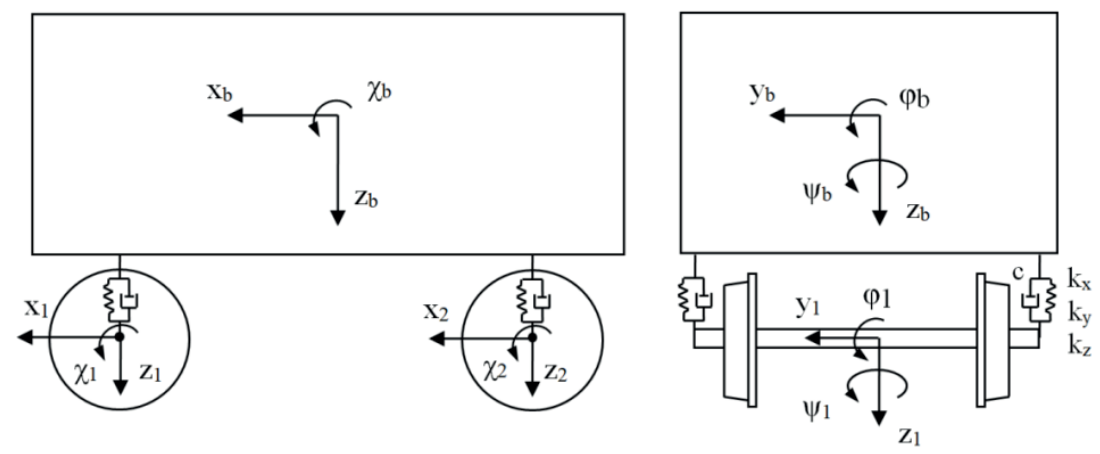

Figure 2 Physical model of a double wheelset wagon

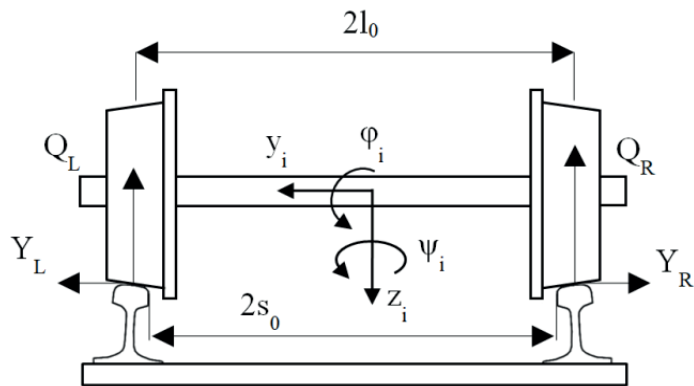

Figure 3 Illustration of a wheelset in track

The presented problem of a vehicle's dynamic behaviour and wheel wear requires including vibrations of the body and wheelsets, because they affect changes of the wheel loads on the rails and consequently the variations of the contact forces values. The general structure of the system of equations, describing the vibrating motion, is represented by Equation (1):

$M \ddot{q}+C \dot{q}+K q=p(t, q, \dot{q})$

where: $M$ - inertia matrix, $C$ - damping matrix, $K$ - stiffness matrix, $q$ - vector of generalised coordinates describing motion of a solid (translations and rotations), $\dot{q}$ - vector of generalised velocities, $p(t, q, \dot{q})$ - vector of forces (moments), which can be treated as the sum of two vectors:

$p(t, q, \dot{q})=f(t)+h(q, \dot{q})$

where: $f(t)$ - vector of exciting forces, $h(q, \dot{q})$ - vector of forces depending nonlinearly on displacements and velocities of the system, including the contact forces.

Kinematic constraints on the wheelset are a result of its interaction with a rigid track. As a consequence, the vertical displacement $z$ and roll angle $\varphi$ are related to lateral displacement of the wheelset $y$ and its yaw angle $\psi$. Angle of rotation $\chi$ accounts for the coordinate describing position of the wheelset's mass centre along track $x$. The form of constraints is nonlinear and depends on the geometric parameters of the wheelset and track, including track gauge, track cant, wheel and rail profiles and the wheelset tape circle distance.

To express equations of motion of a wheelset, its schematic illustration is depicted in Figure 3, containing the selected force vectors and geometric quantities.
Equations of a wheelset in motion, including the elements of primary suspension, may have a different form, bearing in mind the number of degrees of freedom or the model of contact between the wheel and the rail. Following Chudzikiewicz [27], the simplified equations of motion of the $i$-th wheelset can be written in the form:

$$
\begin{aligned}
& m \ddot{y}_{i}=Y_{L i}+Y_{R i}-\left(Q_{L i}+Q_{R i}\right) \Theta_{t}+P_{y i}-m \frac{v^{2}}{R_{i}}, \\
& I_{z} \ddot{\psi}_{i}=\left(F_{x L i}-F_{x R i}\right) s_{i}+M_{z i}-I_{z}\left(\frac{1}{R_{i}}-\frac{1}{R_{i+1}}\right) \frac{v^{2}}{2 l_{0}} \\
& I_{y} \ddot{X}_{i}=F_{x L i} \cdot r_{L i}+F_{x R i} \cdot r_{R i}
\end{aligned}
$$

where:

$v$ - vehicle velocity $[\mathrm{m} / \mathrm{s}], m$ - wheelset mass $[\mathrm{kg}], I_{y}, I_{z}$ wheelset polar and yaw moment of inertia $\left[\mathrm{kg} \cdot \mathrm{m}^{2}\right], l_{0}$ - half of the wheels' tape circles distance [m], $s_{i}$ - current semi track gauge [m], $R_{i}$ - track curve radius (in $i$-th wheelset position) [m], $r_{L i}, r_{R i}$ - left and right wheel rolling radii [m], $Y_{L i}, Y_{R i}$ - left and right wheel/rail lateral forces (parallel to the track plane) $[\mathrm{N}], Q_{L i}, Q_{R i}$ - left and right wheel/ rail vertical forces $[\mathrm{N}], F_{x L i}, F_{x R i}$ - left and right wheel/ rail longitudinal creep forces [N], $\Theta_{t}$ - track cant [rad], $P_{y i}$ - lateral wheelset suspension forces $[\mathrm{N}], M_{z i}$ - yaw bogie suspension moment [Nm].

\subsection{The wheel-rail contact}

The wheel-rail contact zone, whose area is approximately $1 \mathrm{~cm}^{2}$, is an interface of the two subsystems: vehicle and track. The forces generated in the contact area and transmitted to both subsystems are vital from the point of view of a vehicle dynamics, since in general, 
they determine vehicle's behaviour in track and properties such as running stability and wear of wheels and rails. Their unfavourable distribution, e.g. due to wear of a wheel and/or rail profiles, can increase the risk of derailment. Mathematical description of the contact force generation mechanism is complicated due to the fact that all the contact parameters strongly depend on the wheel and rail geometry and that in some circumstances multiple points of contact may occur.

In general, the current approach to the study of contact between the wheel and rail can be divided into two problems:

- normal problem - location and size of the contact patch and normal stresses distribution (solution based mainly on Hertz contact theory [12-13]),

- tangential problem - calculation of tangent stresses and values of tangent forces.

Analysis of the normal problem and its solution is necessary for the formulation of the tangent problem. Mechanism of contact forces generation, tangent to the contact plane, can be explained due to a difference in strain rates of the two bodies in the contact region [28], caused by deviations of a wheel from pure rolling. Such forces are exerted by a wheel on a rail when a tractive/braking torque is applied to the wheel, in the case of curving (yaw angle) or when suspension lateral forces act on a wheelset. As a result, the contact area is thus divided into an adhesion zone (stick) and a slip zone. Depending on the conditions, the contact patch is divided into different proportions, into the area in which the stick and the slip area occur. The size of the slip area depends on the geometry of the wheel and rail in the contact patch, normal and lateral forces, as well as the friction coefficient. The zone, in which slip of interacting surfaces occurs, has a direct effect on their wear. To express the relative difference of pure rolling and rolling with sliding, Carter defined creep (or creepage) in the longitudinal direction, which the term was later extended to the lateral direction along with spin creep. Longitudinal $\gamma_{x}$, lateral $\gamma_{y}$ and spin creepage $\omega_{s p}$ can be defined, basing on Wickens [17], as follows:

$$
\begin{aligned}
& \gamma_{x}=\frac{V_{x}^{w}-V_{x}^{r}}{\frac{1}{2}\left(V_{x}^{w}+V_{x}^{r}\right)}, \\
& \gamma_{y}=\frac{V_{y}^{w}-V_{y}^{r}}{\frac{1}{2}\left(V_{y}^{w}+V_{y}^{r}\right)}, \\
& \omega_{s p}=\frac{\Omega_{z}^{w}-\Omega_{z}^{r}}{\frac{1}{2}\left(V_{y}^{w}+V_{y}^{r}\right)},
\end{aligned}
$$

where:

$V_{x}^{w}, V_{y}^{w}$ - rigid body velocities of the wheel in the $x$ and $y$ directions [m/s], respectively; $V_{x}^{r}, V_{y}^{r}$ - rigid body velocities of the contact point of the rail in $y$-direction $[\mathrm{m} / \mathrm{s}] ; \Omega^{w}{ }_{z}, \Omega^{r}$ angular velocities of the wheel and rail about $z$-axis $[\mathrm{rad} / \mathrm{s}]$.

The contact forces $F_{x}$ (longitudinal), $F_{y}$ (lateral) are functions of creep and thus also called the creep forces. The algorithms of creep forces generation emerged in the 20th century and have established the basis for the codes implemented in the rail vehicle dynamics simulation software. Kalker's simplified algorithm FASTSIM [29], based on the 'stripes theory', is the most widely used in simulations due to sufficient accuracy for engineering purpose and low computational costs. In this algorithm, the elliptical contact zone is divided into parallel longitudinal stripes of width $\Delta y_{i}$ and length along the $x$-axis dependent on the ellipse size. Moreover, all the stripes are divided into the same number of elements and stress calculation is initiated from ellipse edge, element by element [12].

For small values of the creepages and spin, there is a linear relationship between the creep forces and the creepages. Values of those forces can be calculated using other Kalker's algorithm, the so-called Linear Theory [12-13, 27]:

$\left[\begin{array}{l}F_{x} \\ F_{y} \\ M\end{array}\right]=-G a b\left[\begin{array}{ccc}C_{11} & 0 & 0 \\ 0 & C_{22} & \sqrt{a b} C_{23} \\ 0 & -\sqrt{a b} C_{23} & a b C_{33}\end{array}\right]\left[\begin{array}{c}\gamma_{x} \\ \gamma_{y} \\ \omega_{s p}\end{array}\right]$

where:

$C_{11}, C_{22}, C_{23}, C_{33}$ - tabularized Kalker's microslip coefficients; $\mathrm{G}$ - shear modulus [Pa]; $a$ and $b$-contact ellipse semi-axes [m].

The lateral components of creep forces must be projected onto the track plane and summed up to give the guiding force $\mathrm{Y}$ [12].

\section{Simulation conditions}

\subsection{Vehicle model}

Study of the effect of self-lubricating coatings on vehicle dynamics and wheel wear was carried out on a multibody model representing a two-axle goods wagon. Parameters of the model are derived from the Es series 3W/1 goods wagon, fully laden (Table 1). The axle load is 22.3 tons and the wheels have a standard S1002 profile.

The vehicle model was created in the VI-Rail software, which is based on ADMAS multibody simulation environment. The model consists of inertial elements (rigid bodies) representing wheelsets, axle boxes and body, which are connected by means of joints and massless spring and damping elements. The ADAMS software generates automatically and solves equations of motion for individual inertial elements of a complex mechanical system. The dynamic behaviour of the elements of the system is described in ADAMS environment by means of a system of differential-algebraic equations derived from the EulerLagrange formalisms presented in a general form [30]:

$\frac{d}{d t}\left(\frac{\partial L}{\partial \dot{q}}\right)-\frac{\partial L}{\partial q}+\Phi_{q}^{T} \lambda=Q$,

where:

$q$ - vector of generalized coordinates; $L$ - Lagrangian (difference of kinetic and potential energy: $L=T-V$ ); 
Table 1 Parameters of the two-axle good wagon

\begin{tabular}{|c|c|c|}
\hline parameter & value & unit \\
\hline body mass & 40770 & $\mathrm{~kg}$ \\
\hline body moment of inertia $I_{x x}$ & $35 \cdot 10^{3}$ & $\mathrm{~kg} \cdot \mathrm{m}^{2}$ \\
\hline body moment of inertia $I_{y y}$ & $220 \cdot 10^{3}$ & $\mathrm{~kg} \cdot \mathrm{m}^{2}$ \\
\hline body moment of inertia $I_{z z}$ & $220 \cdot 10^{3}$ & $\mathrm{~kg} \cdot \mathrm{m}^{2}$ \\
\hline wheelset mass & 1925 & $\mathrm{~kg}$ \\
\hline wheelset moment of inertia $I_{x x}$ & 950 & $\mathrm{~kg} \cdot \mathrm{m}^{2}$ \\
\hline wheelset moment of inertia $I_{y y}$ & 150 & $\mathrm{~kg} \cdot \mathrm{m}^{2}$ \\
\hline wheelset moment of inertia $I_{z z}$ & 950 & $\mathrm{~kg} \cdot \mathrm{m}^{2}$ \\
\hline spring longitudinal stiffness $k_{x}$ & $12 \cdot 10^{6}$ & $\mathrm{~N} / \mathrm{m}$ \\
\hline spring lateral stiffness $\mathrm{k}_{\mathrm{y}}$ & $640 \cdot 10^{3}$ & $\mathrm{~N} / \mathrm{m}$ \\
\hline spring vertical stiffness $k_{z}$ & $1.8 \cdot 10^{6}$ & $\mathrm{~N} / \mathrm{m}$ \\
\hline vertical damping (one damper) & $100 \cdot 10^{3}$ & $\mathrm{Ns} / \mathrm{m}$ \\
\hline wheelset base & 5.2 & $\mathrm{~m}$ \\
\hline wheel radius & 0.5 & $\mathrm{~m}$ \\
\hline
\end{tabular}

$\Phi_{q}$ - Jacobian matrix of constraints; $\boldsymbol{\lambda}$ - vector of Lagrange multipliers;

$Q$ - vector of external forces.

Systems of nonlinear differential equations are solved by the ADAMS solver numerically, mainly using the NewtonRaphson method. The method of creep-force computation, implemented in the simulation software, is based on the Kalker's FASTSIM algorithm. The code uses the actual wheel and rail profile and calculates the actual contact kinematics at each simulation step. Moreover, it models non-elliptical contact zones, as well as multiple contact patches. Contact stiffness is found according to Boussinesq formulation.

\subsection{Self-lubricating coating model}

In general, the simulation wear analyses of the wheel and rail profiles known from literature, assumed constant value of the wheel-rail coefficient of friction profiles, not taking into account lateral position of the wheelset relative to the track. In the case of applying the self-lubricating coating to the wheel flange, contact conditions will change depending on the location of the point (area) of contact. In this case, the coefficient of friction, for the area covered with the coating, is different, while the other coefficient value is along the wheel tread profile. Undoubtedly, this will have a significant impact on the wear rate of wheel and rail profiles.

The proposed model of the self-lubricating layer describes two values of friction coefficient [31-32]:

- $\mu_{1}=0.4$ for the wheel tread-rail contact,

- $\mu_{2}=0.1$ for the wheel flange-rail contact.

In order to express it mathematically, it is assumed that the coatings would be applied on the wheels' flanges to minimize friction and as a consequence wheel/rail wear: $\mu=\left\{\begin{array}{l}\mu_{1} \text { for }-6 \mathrm{~mm}<y<6 \mathrm{~mm} \\ \mu_{2} \text { for } y \leq-6 \mathrm{~mm} \wedge y \geq 6 \mathrm{~mm}\end{array}\right.$.

The transition between $\mu_{1}$ and $\mu_{2}$ is smoothed with software's in-built spline function. The value of $6 \mathrm{~mm}$ has been set based on the analysis of the wheel-rail contact points location with respect to the wheelset lateral displacement. The wheelset lateral shift of $6 \mathrm{~mm}$ corresponds to location of a contact point on a flange root [13]. Preliminary simulation tests have shown that for values lower than $6 \mathrm{~mm}$ there exists a very high risk of derailment, expressed in higher values of $Y / Q$ (Nadal formula - quotient of lateral to vertical force).

The starting point for considering the wear model of a wheelset with a self-lubricating coating is the measure called the wear number $\left(W_{n}\right)$ based on the widely used T-gamma energy model, whose assumption is the proportional relationship between the amount of worn material and the dissipated energy in the wheel-rail contact zone [33]:

$W_{n}=F_{x} \gamma_{x}+F_{y} \gamma_{y}, \quad[\mathrm{~N}]$

The spin component $M \omega_{s p}$ in Equation (12) is neglected due to its low value compared to longitudinal and lateral components. In contrast to the classic wear model of Archard [34], the T-gamma model comprises friction coefficient between wheel and rail implicitly. The values of the developed creep forces $F_{x}$ and $F_{y}$ are limited by the friction coefficient $\mu$ and normal force $N$ in the contact zone:

$F_{\max }=\mu N,[\mathrm{~N}]$.

In the simulation tests, a simplifying assumption, based on immutability of material parameters, such as Young's modulus or Poisson's coefficient, was adopted - i.e. the thin 
Table 2 Track profiles (TC - transition curve)

\begin{tabular}{|c|c|c|c|}
\hline \multicolumn{2}{|c|}{ scenario 1} & \multicolumn{2}{|c|}{ scenario 2} \\
\hline distance (m) & radius (m) & distance (m) & radius (m) \\
\hline 0 & $\infty$ & 0 & $\infty$ \\
\hline 29.75 & $\infty / \mathrm{TC}$ & 50 & $\infty / \mathrm{TC}$ \\
\hline 30 & 150 (right) & 85 & 1200 (right) \\
\hline 109.75 & 150 (right)/TC & 485 & 1200 (right) /TC \\
\hline 110 & $\infty$ & 510 & $\infty$ \\
\hline 120.92 & $\infty / \mathrm{TC}$ & 560 & $\infty / \mathrm{TC}$ \\
\hline 120.98 & -150 (left) & 595 & -1200 (left) \\
\hline 200.92 & -150 (left)/TC & 995 & -1200 (left) /TC \\
\hline 200.98 & $\infty$ & 1030 & $\infty$ \\
\hline 220 & $\infty$ & 1080 & $\infty$ \\
\hline
\end{tabular}
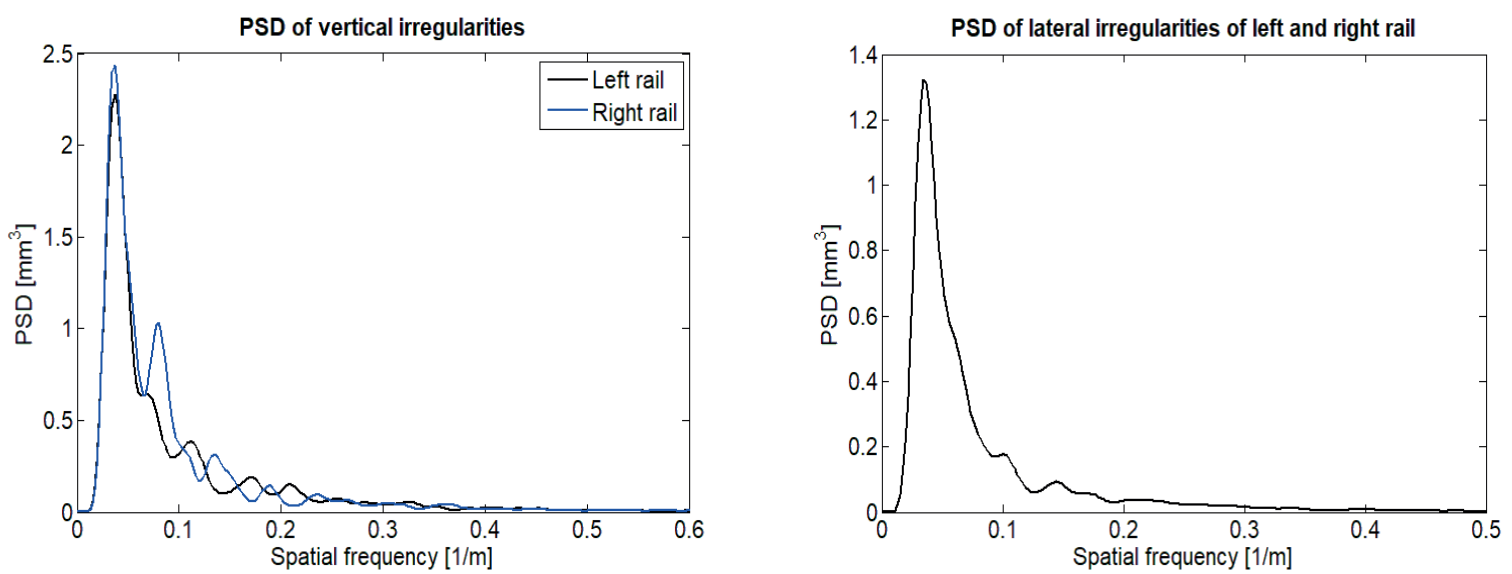

Figure 4 Power spectral densities of the track irregularities

self-lubricating bronze layer has the same properties as a wheel material.

\subsection{Simulation scenarios}

Simulation experiments have been carried out according to the following scenarios:

- Scenario 1 - vehicle moving on track with curves of $\mathrm{R}=$ $150 \mathrm{~m}$ radii at $v=30 \mathrm{~km} / \mathrm{h}$.

- Scenario 2 - vehicle moving on track with curves of $\mathrm{R}=$ $1200 \mathrm{~m}$ radii at $v=80 \mathrm{~km} / \mathrm{h}$.

The proposed scenarios reflect the curve radii characteristic for mountain routes (scenario 1, e.g. route Cracow-Zakopane in Poland) and common in lowland and hilly areas (scenario 2). The routes were designed to comprise a tangent track and $\mathrm{S}$ curve sections of normal gauge $(1435 \mathrm{~mm})$. The track cant in both scenarios is equal to $15 \mathrm{~cm}$ and rail profile is standard, unworn UIC60. Track profiles are described in Table 2.

The track vertical stiffness was assumed as infinite. The vertical and lateral track irregularities correspond to a medium quality of maintenance level. Statistical parameters of the track irregularities are shown in Table 3 , whereas the power spectral densities of irregularities are depicted in Figure 4. Apart from the track geometry, track irregularities are an additional source of the wheelset-track dynamic interaction, causing vibrations of the model's inertial elements and thus grater variations of the contact forces.

\section{Simulation study results}

A quantitative comparison of the dynamic behaviour of the wagon with the standard wheelsets and the wagon with wheelsets covered with self-lubricating coatings is shown in Figures 5-7. Particularly important in a rail vehicle dynamics analysis is lateral displacement of the wheelset relative to the track centreline. In curves without gauge widening (radius $R>250 \mathrm{~m}$ ) values exceeding $9 \mathrm{~mm}$ might indicate severe wheel flange-rail contact and high risk of derailment. In the case of scenario $1(R=150 \mathrm{~m})$, lateral shifts of the leading and trailing wheelset with self-lubricating coatings are lower, however, these wheelsets are displaced in opposite directions compared to the standard wheelsets (Figure 5). Unfortunately, in the curves of greater radii $(R$ $=1200 \mathrm{~m}$, scenario 2 ), results obtained for the vehicle with coatings are worse, i.e. 3 - $4 \mathrm{~mm}$ higher displacements for both wheelsets are observed (Figure 6).

Developed lateral forces are crucial to guiding the wheelset in track, albeit too high values negatively affect 
Table 3 Height of the track irregularities

\begin{tabular}{|c|c|c|c|c|}
\hline height (mm) & left Y & left Z & right $\mathrm{Y}$ & right $\mathrm{Z}$ \\
\hline $\min$. & -8.1 & -11.1 & -8.1 & -11.5 \\
\hline $\max$ & 8.8 & 13.2 & 8.8 & 12.5 \\
\hline standard dev. & 3.0 & 4.2 & 3.0 & 4.5 \\
\hline
\end{tabular}
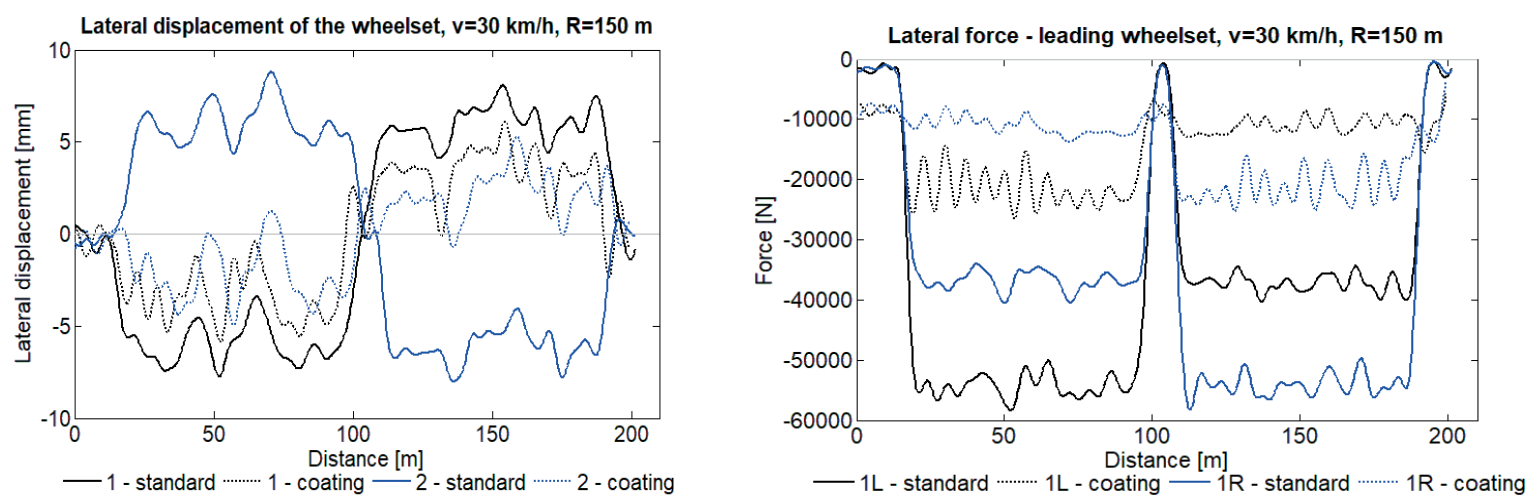

Figure 5 Lateral displacement of both wheelsets (left) and lateral force of the leading wheelset (right) - scenario 1
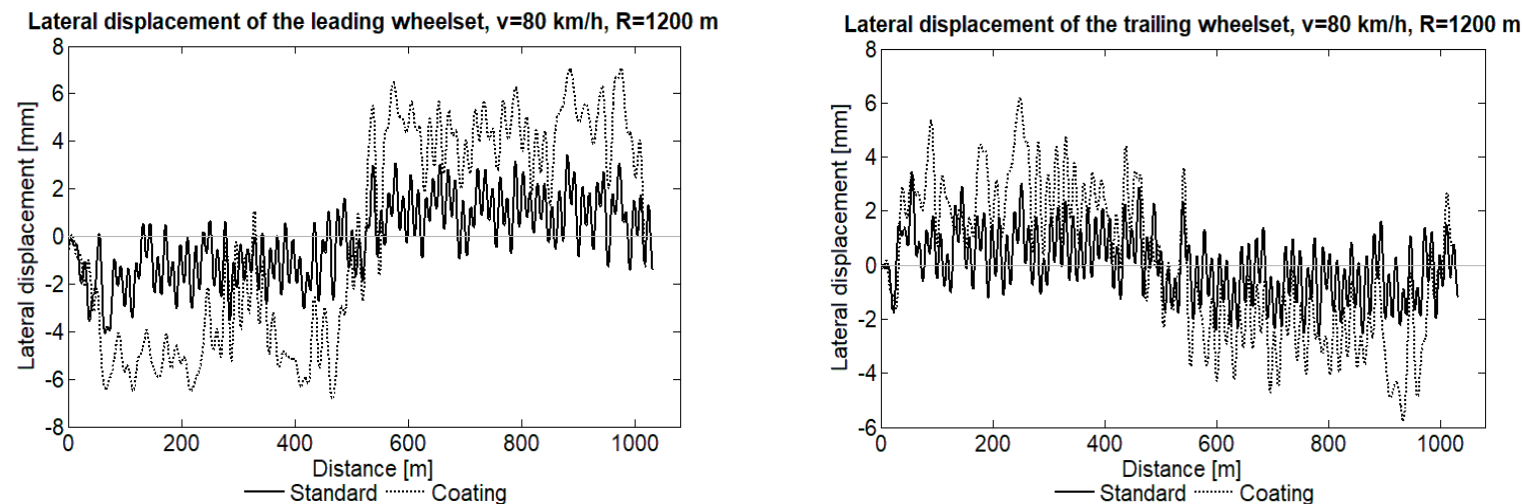

Figure 6 Lateral displacement of the leading (left) and trailing wheelset (right) - scenario 2
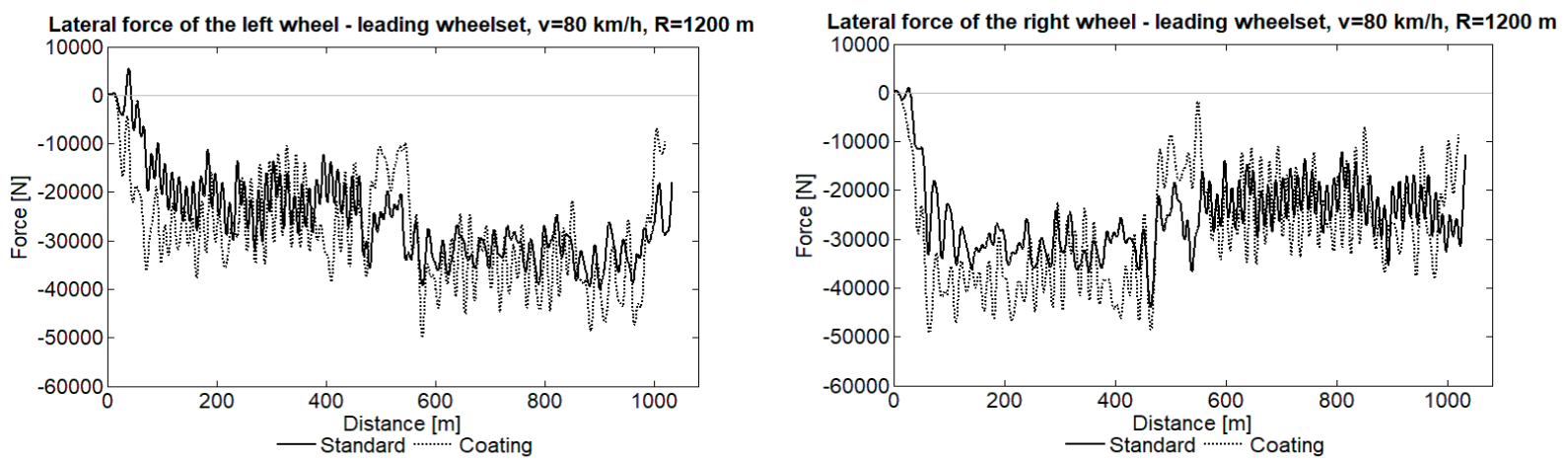

Figure 7 Lateral force of the left and right wheel of the leading wheelset - scenario 2

safety against derailment and contribute to accelerated wheel wear. In scenario 1 a significant decrease of lateral forces is observed, which is the result of the lower friction coefficient and lateral displacement (Figure 7 bottom). On the other hand, in the curves of $R=1200 \mathrm{~m}$, the wheelsets with self-lubricating coatings are affected by noticeably higher lateral forces, being an objectionable feature. The differences in force values for both wheelsets are up to cca. $10 \mathrm{kN}$.

Following analysis of the lateral forces, one can investigate the lateral acceleration of the wheelsets. The greater lateral forces in the case of wheelset with coating entail the higher values of acceleration (Figure 8). This fact could have a negative effect on the ride comfort in the case 

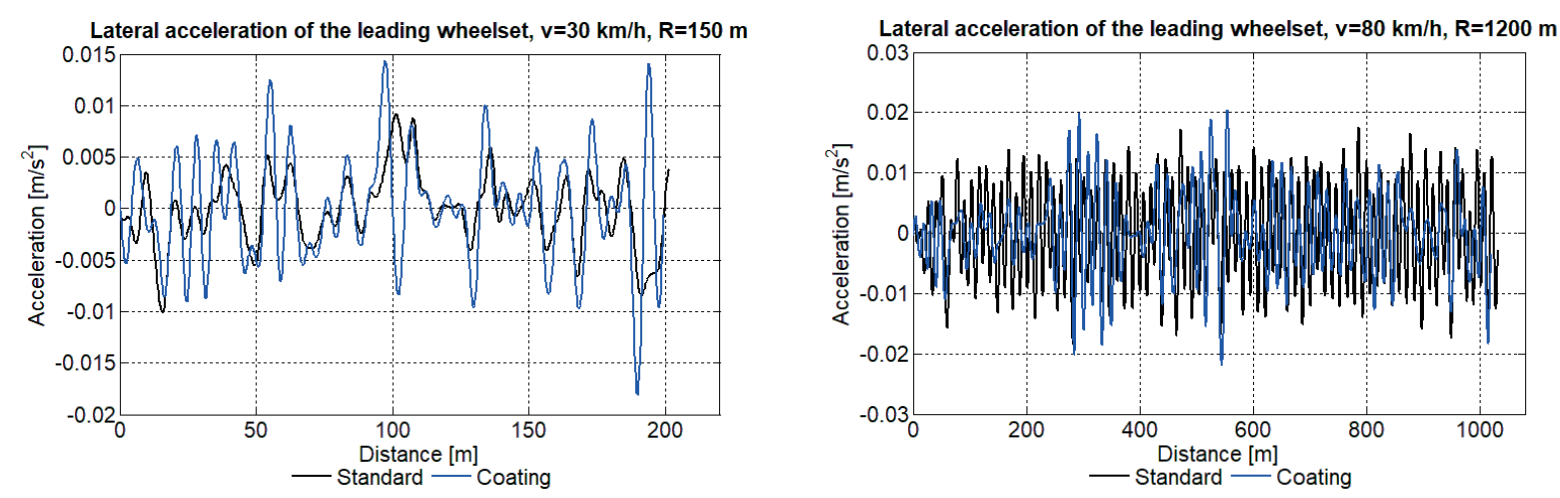

Figure 8 Lateral acceleration of the leading wheelset - scenario 1 (left), scenario 2 (right)
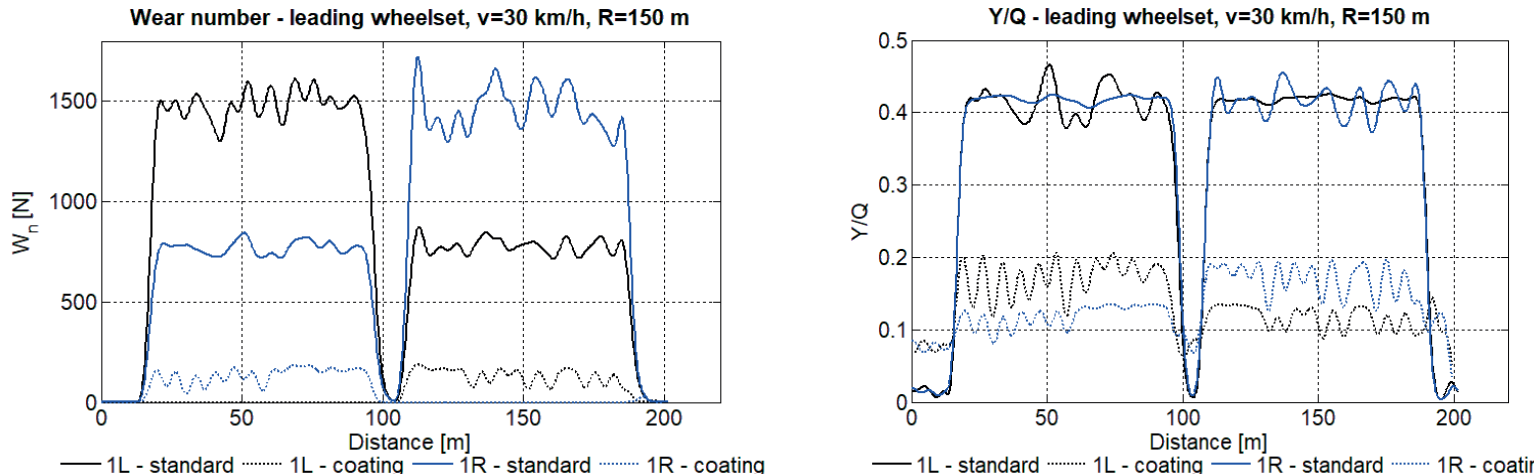

Figure 9 Comparison of the wear number and mean $Y / Q$ values - scenario 1
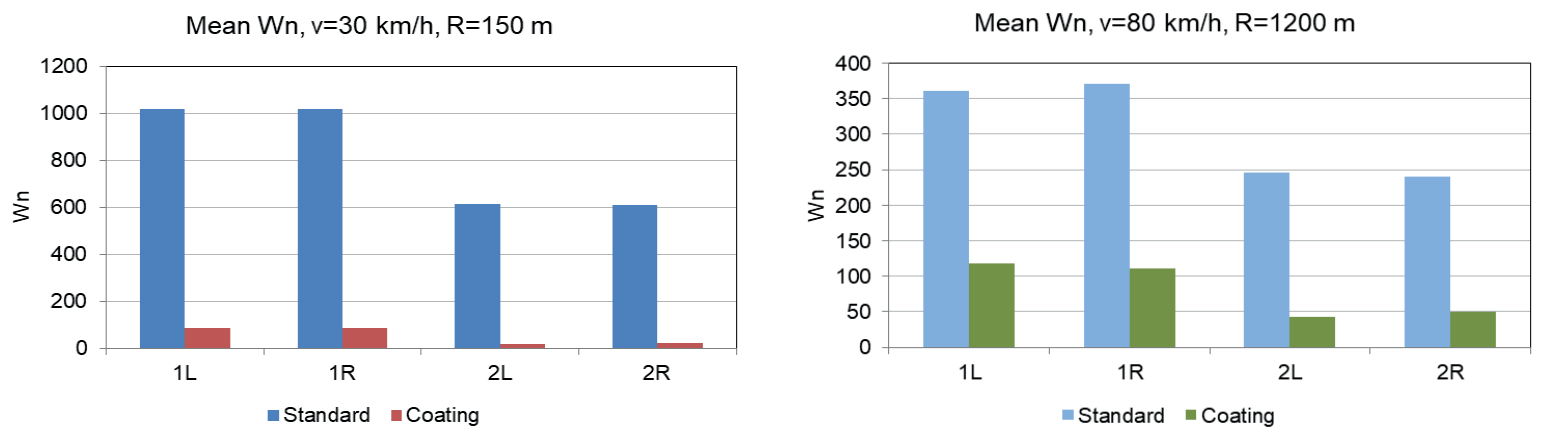

Figure 10 Comparison of the mean wear number $W_{n}$ values - scenario 1 (left), scenario 2 (right)
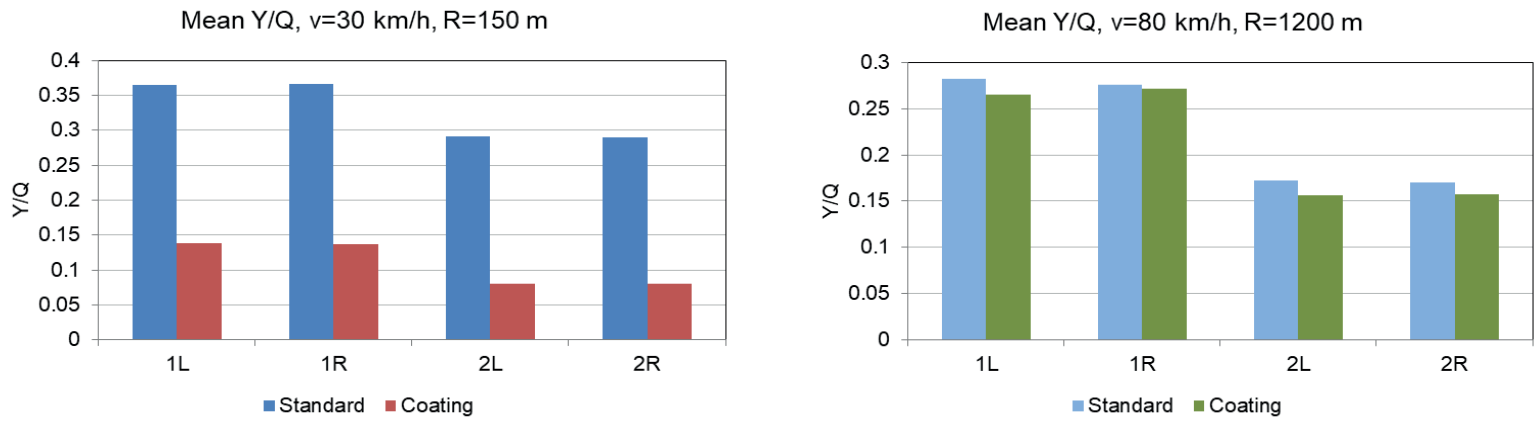

Figure 11 Comparison of mean $Y / Q$ values - scenario 1 (left), scenario 2 (right)

of passenger coaches, nonetheless, it can be omitted when dealing with the transport of goods.

The next part of the analysis focuses on parameters estimating the wheel wear - $W_{n}$ and safety against derailment
- $Y / Q$. Examples of recorded values of $W_{n}$ and $Y / Q$ from scenario 1 are presented in Figure 9.

Predicted mean wear rate of the wheels' profiles, based on the T-gamma model, is lower for the wheelsets 
with coatings. Especially low values of $W_{n}$ are calculated for scenario 1 , in which the wear is expected to be reduced up to cca. 10 times for the wheels of the leading wheelset (Figure 10 left). The wear number, obtained in scenario 2 for the wheelsets with coatings, is also lower despite the higher lateral forces (Fig. 10 right). In this case, the favourable $W_{n}$ values are obtained due to the lower creep than in scenario 1. Along with increasing curve radius, application of the self-lubricating coatings should still be beneficial - the wear would be up to 5 times lower (for the wheels of the trailing wheelset).

In order to assess influence of the self-lubricating coatings on safety against derailment, the mean values of $Y / Q$ forces ratio are compared in Figure 11. A similar dependence is noticed as in the case of $W_{n}$ comparison - the smaller curve radius the greater the benefit of using coatings. In scenario 1 safety against derailment was substantially improved, yet the results obtained from scenario 2 show that coatings have only slightly positive effects on the $Y / Q$ ratio.

\section{Conclusions}

Phenomenon of the wheel and rail wear generates significant operating costs and is a problem from the point of view of availability of the transport means and infrastructure. One of the most recent and potential solutions to reduce wear is application of the self-lubricating coatings on the wheel flange. These coatings reduce the friction coefficient of the wheel-rail interface.
Dynamic properties of the rail vehicle cannot remain unaffected due to modification of the friction coefficient. The aim of the study presented herein was an assessment of the self-lubricating coatings impact on dynamic behaviour of a vehicle, with special regard to safety against derailment and wheel wear.

The simulation tests were performed on a two-axle goods wagon, considering randomly generated geometrical track irregularities, in order to model the medium maintenance level. The simulation results allow formulating the conclusion that dynamic properties of a vehicle with wheels covered with the self-lubricating coatings enable the use of such a vehicle in safe conditions, not worse than in the case of a vehicle with standard wheels.

In the case of wagons with wheelsets covered with the self-lubricating coatings, the wear of the wheels' surface should be at least 2 times lower compared to wagons in which the wheels have not been covered with such a coating. Consequently, the lifecycle of the wheelset should be extended, taking into account only wear of the wheel profiles. Benefits, resulting from applying the selflubricating coatings, will be particularly evident during the operation of vehicles on routes containing a significant number of low-radii curves, where the predicted wear would be up to 5 times lower.

The next actions taken in the study of the selflubricating coatings should focus on evaluating their durability in operational conditions and comparing the costs and frequency of applying/replacing the new layers to the costs of the wheel reprofiling.

\section{References}

[1] POMBO, J. Application of a computational tool to study the influence of worn wheels on railway. Journal of Software Engineering and Applications [online]. 2012, 5(2), p. 51-61. ISSN 1945-3116. Available from: https://doi.org/10.4236/jsea.2012.52009

[2] HAUSER, V., NOZHENKO, O., KRAVCHENKO, K., LOUlOVA, M., GERLICI, J., LACK, T. Impact of three axle boxes bogie to the tram behaviour when passing curved track. Procedia Engineering [online]. 2017, 192, p. 295300. ISSN 1877-7058. Available from: https://doi.org/10.1016/j.proeng.2017.06.051

[3] MACIEJEWSKI, I., KRZYZYNSKI, T., CHUDZIKIEWICZ, A., SOWINSKA, M. Concept of the control system for a single wheelset with independently rotating wheels driven by induction motors. Machine Dynamics Research. 2016, 40(1), p. 53-63. ISSN 2080-9948.

[4] MELNIK, R., SOWINSKI, B. Analysis of dynamics of metro vehicle model with differential wheelsets. Transport Problems [online]. 2017, 12(3), p. 113-124. ISSN 1896-0596. Available from: https://doi.org/10.20858/tp.2017.12.3.11

[5] OLOFSSON, U., ZHU, Y., ABBASI, S., LEWIS, R., et al. Tribology of the wheel-rail contact - aspects of wear, particle emission and adhesion. Vehicle Systems Dynamics [online]. 2013, 51(7), p. 1091-1120. ISSN 1744-5159. Available from: https://doi.org/10.1080/00423114.2013.800215

[6] SUNDH J. On wear transitions in the wheel-rail contact. Doctoral thesis. Stockholm, Sweden: KTH Royal Institute of Technology, 2009.

[7] NILSSON, R. On wear in rolling/sliding contacts. Doctoral thesis. Stockholm, Sweden: KTH Royal Institute of Technology, 2005.

[8] Plasma Systems [online] [accessed 2020-02-18]. Available from https://www.plasmasystem.pl/en/industries/railtransport

[9] DROZDZIEL, J., SOWINSKI, B. Simulation of railway track deterioration influenced by ballast stiffness and dry friction. In: Computers in railways XI. Southampton (UK): WIT Press, 2008. ISBN 978-1-84564-126-9, p. 693-702. 
[10] TUTUMLUER, E., QIAN, Y., HASHASH, Y. M. A., GHABOUSSI, J., DAVIS, D. D. Discrete element modelling of ballasted track deformation behaviour. International Journal of Rail Transportation [online]. 2013, 1(1-2), p. 57-73. ISSN 2324-837, eISSN 2324-8386. Available from: https://doi.org/10.1080/23248378.2013.788361

[11] KOZIAK, S., CHUDZIKIEWICZ A., OPALA, M., MELNIK, R. Virtual software testing and certification of railway vehicle from the point of view of their dynamics. Transportation Research Procedia [online]. 2019, 40, p. 729-736. ISSN 2352-1465. Available from: https://doi.org/10.1016/j.trpro.2019.07.103

[12] IWNICKI, S. Hanbook of railway vehicle dynamics. Boca Raton (FL): CRC Press, 2006. ISBN 9780849333217.

[13] KNOTHE, K., STICHEL, S. Rail vehicle dynamics [online]. Cham, Switzerland: Springer 2017. ISBN 978-3-319-45376-7. Available from: https://doi.org/ 10.1007/978-3-319-45376-7

[14] KONOWROCKI, R., WALCZAK, S. Influence of flexibility parameters of wheels and wheelset on the railway bogie dynamics. Experimental and theoretical investigations. Machine Dynamics Research. 2017, 41(1), p. 41-53. ISSN 2080-9948.

[15] LACK, T., GERLICI, J. A modified strip method to speed up the tangential stress between wheel and rail calculation. Applied Mechanics and Materials [online]. 2014, 486, p. 371-378. ISSN 1662-7482. Available from: https://doi.org/10.4028/www.scientific.net/AMM.486.371

[16] OPALA, M. Evaluation of bogie centre bowl friction models in the context of safety against derailment simulation predictions. Archive of Applied Mechanics [online]. 2018, 88(6), p. 943-953. ISSN 0939-1533. Available from: https://doi.org/10.1007/s00419-018-1351-4

[17] WICKENS, A. Fundamentals of rail vehicle dynamics: guidance and stability. 1 ed. Lisse: Swets, 2003. ISBN 902651946X.

[18] ZBOINSKI, K., DUSZA, M. Bifurcation analysis of 4-axle rail vehicle models in a curved track. Nonlinear Dynamics [online]. 2017, 89(2), p. 863-885. ISSN 1573-269X. Available from: https://doi.org/10.1007/s11071-017$3489-\mathrm{y}$

[19] FIRLIK, B., CZECHYRA, B., CHUDZIKIEWICZ, A. Condition monitoring system for light rail vehicle and track. Key Engineering Materials [online]. 2012, 518, p. 66-75. ISSN 1662-9795. Available from: https://doi.org/10.4028/ www.scientific.net/KEM.518.66

[20] DIZO, J., STEISUNAS, S., BLATNICKY, M. Vibration analysis of a coach with the wheel-flat due to suspension parameters changes. Procedia Engineering [online]. 2017, 192, p. 107-112. ISSN 1877-7058. Available from: https://doi.org/10.1016/j.proeng.2017.06.019

[21] DUMITRIU, M., GHETI, M. A. Evaluation of the vertical vibrations behaviour of the bogie at failure of the dampers in the primary suspension of the railway vehicle. MATEC Web of Conferences [online]. 2018, 178, p. 1-6. ISSN 2261-236X. Available from: https://doi.org/10.1051/matecconf/201817806001

[22] MELNIK, R., KOZIAK, S. Rail vehicle suspension condition monitoring - approach and implementation. Journal of Vibroengineering [online]. 2017, 19(1), p. 487-501. ISSN 2538-8460. Available from: https://doi.org/10.21595/ jve.2016.17072

[23] CHUDZIKIEWICZ, A., KORZEB, J. Simulation study of wheels wear in low-floor tram with independently rotating wheels. Archive of Applied Mechanics [online]. 2018, 419(88), p. 175-192. ISSN 0939-1533. Available from: https://doi.org/10.1007/s00419-017-1301-6

[24] LEWIS, R., DWYER-JOYCE, R. S., LEWIS, S. R., HARDWICK, C., GALLARDO-HERNANDEZ, E. A. Tribology of the wheel-rail contact: the effect of third body materials. The International Journal of Railway Technology [online]. 2012, 1(1), p. 167-194. ISSN 2049-5358. Available from: http://dx.doi.org/10.4203/ijrt.1.1.8

[25] TOMBERGER, C., DIETMAIER, P., SEXTRO, W., SIX, K. Friction in wheel-rail contact: a model comprising interfacial fluids, surface roughness and temperature. Wear [online]. 2011, 271(1-2), p. 2-12. ISSN 0043-1648. Available from: https://doi.org/10.1016/j.wear.2010.10.025

[26] ZHU, Y. Adhesion in the wheel-rail contact under contaminated conditions. Licentiate thesis. Stockholm, Sweden: KTH Royal Institute of Technology, 2011.

[27] CHUDZIKIEWICZ, A. Evolution of the simulation study of a railway wheel profile through wear. In: 2nd Mini Conference on Contact Mechanics and Wear of Rail/Wheel Systems: proceeding. Budapest: University of Technology and Economics, 1996. ISBN 963-420-509-7, p. 207-214.

[28] GARG, V. K., DUKKIPATI, R. V. Dynamics of railway vehicle systems. Toronto (T.O.): Academic Press, 1984. ISBN 0-12-275950-8.

[29] KALKER, J. J. Fast algorithm for the simplified theory of rolling contact. Vehicle System Dynamics [online]. 1982, 11(1), p. 1-13. ISSN 1744-5159. Available from: https://doi.org/10.1080/00423118208968684

[30] MCCONVILLE, J. B., MCGRATH, J. F. Introduction to ADAMS theory. Ann Arbor (MI): Mechanical Dynamic Inc., 1998.

[31] CHUDZIKIEWICZ, A., MELNIK, R., GORA, I. Wheelsets' self-lubricating coatings in terms of rail vehicle dynamic properties. Prace Naukowe Politechniki Warszawskiej - Transport [online]. 2019, 124, p. 19-30. ISSN 1230-9265. 
Available from: https://www.wt.pw.edu.pl/Badania-i-nauka/Prace-Naukowe-Politechniki-Warszawskiej-Transport/ Zeszyty/Zeszyt-124

[32] GORA, I. Modeling and simulation testing of dynamic properties of a railway wheelset using innovative selflubricating coatings. Doctoral thesis. Warsaw, Poland: Warsaw University of Technology, 2018.

[33] PEARCE, T. G, SHERRATT, N. D. Prediction of wheel profile wear. Wear [online]. 1991, 144, p. 343-351. ISSN 00431648. Available from: https://doi.org/10.1016/b978-0-444-88774-0.50027-4

[34] ARCHARD, J. F. Contact and rubbing of flat surfaces. Journal of Applied Physics [online]. 1953, 24, p. 981-988. ISSN 1089-7550. Available from: https://doi.org/110.1063/1.1721448 